\title{
Pharmaceutical Product Selection: Application of AHP
}

\author{
Farzana Elahi ${ }^{1}$, Afia Muqtadir ${ }^{1}$, Shahriyar Anam ${ }^{1} \&$ K. Mustafiz ${ }^{1}$ \\ ${ }^{1}$ School of Business, University of Asia Pacific, Dhaka, Bangladesh \\ Correspondence: Shahriyar Anam, School of Business, University of Asia Pacific, Dhaka, Bangladesh. E-mail: \\ shahriyar@uap-bd.edu
}

Received: April 10, 2017

Accepted: June 14, 2017

Online Published: July 18, 2017

doi:10.5539/ijbm.v12n8p193

URL: https://doi.org/10.5539/ijbm.v12n8p193

\begin{abstract}
Pharmaceutical industry caters to the health care needs through manufacturing drugs that cure diseases. With retailers being one of the customers in this industry, it is imperative for any pharmaceutical companyto address the issues concerning their preferences for these drugs to remain competitive in business. This prompts us to investigate the factors that influence their decisions in selecting the pharmaceutical products. This paper aims to identify those factors and rank them through application of analytical hierarchy process (AHP) with the support of the Expert Choice Software version 11.0. In this regard, six factors are identified, namely, quality of products, availability of products, variety of products, delivery deadline, flexibility in quantity, and competitive price that affect the purchasing decision of the retailers. The result indicates that among the chosen six factors, quality of products is ranked first followed by variety of products, availability of products, flexibility in quantity, competitive price, and delivery deadline. Inconsistency level as generated by the synthesis of AHP is found to be $9 \%$ that falls below the threshold value of $10 \%$, signifying to the acceptability of the result. The implications of the findings on the part of the pharmaceutical companies and suggestions for future research are also put forward.
\end{abstract}

Keywords: Pharmaceutical industry, customer satisfaction, analytical hierarchyprocess (AHP), retail pharmacy

\section{Introduction}

Sickness is a common phenomenon in the world and the entire human race of Almighty faces this experience. As there are many diseases prevalent in the community of the globe, pharmaceutical drugs have become an integral part of human existence. The primary purpose of these drugs is to diagnose, cure, andalso prevent various types of diseases. Moreover, drugs prescribed by doctors generally prevent people from having expensive treatment such as undergoing a complex surgery (Zhang \& Soumerai, 2007). For this reason, pharmaceutical industry has concentrated on fulfilling the world's medical needs. These organizations are committed to discovering, developing, manufacturing and marketing innovative medicines that treat diseases and improve health care (Gennaro, 1990). Now-a-days pharmaceutical organizations have made great progress in the treatment of diseases; simultaneously, people's life expectancy has also witnessed an increase by the development of new drugs, resulting into a fierce competition among the companies in the marketplace. In order to be competitive, pharmaceutical companies must be able to manage consumer demands of drugsalong the entire supply chain. Pharmaceutical purchasing activities generally runs along the physician-pharmacist-patients continuum, but current health care systems are going through a transition from a physician-directed system to a consumer-directed one (Matthews, 2001). At the present time, the voice of the consumers is getting more pronounced due to heightened health consciousness and access to information (Castelló, 2003). For this, Pharmaceutical companies require to improve more robust linkage with the retail pharmacies in order to understand the market situation in a timely manner (Ghatari, Mehralian, Zarenezhad, \& Rasekh, 2013). Pharmaceutical industry is very unique as the final consumers (patients) are not the only ones who make purchase decisions and make payment; behind the scene, there are other parties like retail pharmacies, doctors, and regulation authority, which make the network more complicated. This study mainly focuses on retail pharmacies as customer due to the impact of their purchasing decisionsto the overall financial success of the pharmaceutical companies.

In Bangladesh pharmaceutical industry is one of the most profitable, technologically advanced and trusted sectors with its domestic market size in terms of sales is US \$1.29 billion (IDLC Investment Limited, 2013). There are 271 pharmaceutical companies currently operating in the market (Bangladesh Bureau of Statistics, 
2013). At present, the contribution on GDP of this rapidly growing industry is almost $1 \%$ and this is the third largest tax paying sector in the country (Bangladesh's Corporate World, 2013). Over the last five years, this industry has experienced a significant market growth at a cumulative average growth rate of $15 \%$, surpassing both regional and global trend (IDLC Investment Limited, 2013). Actual growth of pharmaceutical industry of Bangladesh accelerated after the promulgation of Drugs Control Ordinance-1982 (with an amendment brought in 1994) and the National Drugs Policy. These bodies mainly focused on safety, efficacy, price limitation and proper use of drugs. This ordinance restricted disproportionate import of drugs which encouraged local companies to increase production of their own products. As a consequence, multinational companies were forced to withdraw from the domestic market. This is borne by the fact that thelocal manufacturers cater to about $98 \%$ of the internal medicine requirements and remaining only $2 \%$ drugs are imported. In addition, Bangladesh exported 30 pharmaceutical items to 88 countries in fiscal 2013-14 (Ahmed, 2015).

In Bangladesh retail pharmacies are committed to meeting the health care services and wellness needs of the people. These retail drug shops are often the first point of contact with the health care system and preferred channel for purchasing medicines for the majority of people (Miller \& Goodman, 2016). Bangladesh is no exception to this. In this country anybody can buy any drugs without any prescription. At present around six systems of medicine are available in the country such as Allopathic, Unani, Homeopathic, Biochemic, Ayurvedic, and Herbal. Currently, 1, 01,917 licensed retail shops are operating across the country. And the present market size is Tk.10000 crore (approx) (Directorate General of Drug Administration, 2013). The primary function of the drug store is to retail sales and service to the end consumer (patient). However, this sector is someway different than many other retail sectors. As part of the health care system, retail pharmacy does not merely follow a traditional supply-and-demand market; rather consider public healthcare service in terms of convenience, low price elasticity, safety, information asymmetry etc (Strong, 2014).

The prime objective of this study is to explore the factors generally considered by the retail pharmacies in Bangladesh while purchasing the drugs from various pharmaceutical companies. For this purpose, a leading domestic pharmaceutical company in Bangladesh is chosen to identify the factors that significantly influence the purchasing decision of the retailers. In this study, analytical hierarchy process (AHP) is applied to rank the relative importance of those factors gathered from the executives working in production, quality control, and marketing departments of the company, and possess knowledge about retailers' choice criteria of pharmaceutical products.Since few studies are done taking the retailers' perspectives into consideration, this study is expected to fill the lacunae in the existing literature, particularly in the field of pharmaceutical sector in Bangladesh.

The paper is organized as follows: the first section addresses the factors affecting the retailer choice decision.In the second section, the paper presents an extensive literature review on the applicability of AHP in diverse areas, and then highlights its use in the chosen field. The third section of this paper has explicated the methodology where analytical hierarchy process (AHP) is discussed. Fourth section presents the study findings and finally section five concludes the article by highlighting a few limitations and offering guidance for the further research direction.

\section{Literature Review}

Originally introduced by Saaty (early 1970s), Analytic Hierarchy Process (AHP) is regarded as a versatile MCDM (multi criteria decision making) tool for its wide applicability. As stated by (Triantaphyllou \& Mann, 1995), "AHP is a decision support tool which can be used to solve complex decision problems. It uses a multi-level hierarchical structure of objectives, criteria, sub criteria, \& alternatives (p.35 - p.44)". According to Subramanian et al. (2012), any problem requiring consideration of qualitative and quantitative factors can be dealt with AHP application.

Communication, interactions or relationship amongst manufacturing companies, government, healthcare customers, and healthcare providers has become very complex and resulted in attention towards value-chain. A review of existing literature reveals that while AHP has been employed in the process of decision-making in this industry, there is a dearth of studies vis-à-vis its application in determining the factors influencing the customers (retail pharmacies) in selecting pharmaceutical products, particularly in the Bangladesh context.Literature survey of AHP application regardingrisk associated in pharmaceutical supply chain is followed by in-depth survey of studies on AHP application on the selection process of pharmaceutical industry.

Kamath et al. (2012) performed a study using AHP on the risks associated in a pharmaceutical supply chain. The risks considered are regulatory risk, inventory risk, counterfeit risk and financial risk. The study reveals that the regulatory risk attains the highest ranking (38.3), closely followed by financial risk (34.2\%), with the other risks i.e., inventory and counterfeit, having relatively lower weights of $16.8 \%$ and $10.7 \%$, respectively. Further, the 
authors consider the four alternatives of risk management strategies, namely, risk reduction, risk, avoidance, risk acceptance and risk transfer. It is found that while for the regulatory and financial risk, the strategies would be the risk transfer, for both counterfeit and inventory risk, risk reduction strategy would be the better option that might be considered by the pharmaceutical companies.

Jaberidoost et al (2015), considering priority, hazard \& probability of risks tried to assess the risk in pharmaceutical industry in Iranian context. Group Analytic Hierarchy Process (AHP) method was applied for risk identification in Iranian pharmaceutical companies. It further stated that the efficiency of the health care system can be affected and supply chain disrupted if there is any risk factor affecting the pharmaceutical industry.

A case study on solving the supplier selection process problem in a generic pharmaceutical using AHP model was conducted by Enyinda (2010). The study assesses that lack of proper selection and evaluation of potential supplierscan retard a firm's supply chain performance and considered AHP as a reliable model for solving the supplier selection process problem.. The findings as obtained through $\mathrm{E} / \mathrm{C}$ software indicate that in the process of supplier selection "Regulatory Compliance" played the most vital role. Quality, risk, cost, supplier profile and service consecutively followed the most favored (regulatory compliance) criteria reinforcing the importance of quality.

Vidal et al. (2010) applied AHP vis-à-vis production and distribution of anti-cancer drugs within a pharmaceutical chemotherapy unit of a French hospital. Aimed at minimizing the cost attendant in a drug preparation process while simultaneously satisfying the patients, the application of AHP helps, by calculating the weights, in identifying the drugs that the unit can produce in advance. The results indicate that patientrelated factors $(46.8 \%)$ are ranked the highest followed by drug-related factors $(32.2 \%)$, and economic factors $(21 \%)$; when these are broken into sub-criteria, drug stability (26.9\%). Bothprescription timehorizon, annual production volume $(21.3 \%)$, drug price $(21 \%)$ constitute more than $90 \%$ of the sub-criteria evaluation.

A study indicating that both quantitative and qualitative criteria play a vital role in the selection Processof global suppliers was conducted by (Tas, 2012). It proposes a fuzzy analytic HierarchyProcess (Fuzzy-AHP) to consider and handle efficiently based on both types of criteria in the selection of global supplier in pharmaceutical industry.

Asamoah et al. (2012),in a study observed that the AHP makes it easier to evaluate, rank and select efficient supplier for pharmaceutical manufacturing firms in a timely and reliable manner. Mainly three criteria - quality, price, and reliability/capacity were chosen to select most efficient supplier. The research findings correlates with other researches emphasizing quality of raw material as the most important attribute in the selection process. Quality scoring the highest score (.6334) proved to be the most emphasized criteria, followed by reliability/capacity (0.2605), and price given the lowest score of 0.161 .

A conceptual framework for addressing the issue of supplier selection and the subsequent order allocation among the selected suppliers was proposed by Haque et al. (2014) in the context of Bangladesh pharmaceutical industry. The framework applies AHP to find out weights of the candidate suppliers based on a few criteria. The LP modeling is subsequently employed for optimum order allocation among selected suppliers, where the objective function was one of maximizing the total value of purchase subject to few constraints, such as, quality, capacity,demand and lead time. The authors observe that the application of such an integrated methodology would significantly help managers working in the pharmaceutical industry indealing with the issue of optimum order allocation among the selected suppliers.

A case study by Yadav et al. (2015) conducted in Nepal worked towards accomplishing three outputs. Firstly, Geometric Mean Induced Bias Matrix (GMIBM) method applied to accelerate the research process and identify inconsistent data. Secondly, Analytical Hierarchy Process (AHP) method applied in selecting specific supplier from four alternatives (Supplier A, Supplier B, Supplier C, and Supplier D) based on following criterianamely, lower risk, reduce cost, better quality, on time delivery and better service. Supplier A was selected based on the achieved highest score of .4788. Supplier C ranked second with the score of .2485 . Thirdly, the Supplier Selection Process (SSP) was developed and further stated that in the process of selecting best supplier SSP can be used an as effective toll.

\section{Methodology}

In this work, analytic hierarchy process (AHP) is used to find out the ranking of the factors concerning the retail pharmacies in their selection of drugs from various pharmaceutical companies.

Developed by Saaty(2000), the AHP is a widely used framework for multi-criteria decision making purposes that 
comprises three steps: first, it decomposes the unstructured problem into a hierarchy of different levels of elements; second, it determines relative worth/priorities of the factors through pair-wise comparison scale; third, it synthesizes the priorities to realize the ultimate goal of the problem at hand. Thus, in this study, at the top of the hierarchy lies the main goal i.e., ascertaining the factors affecting the choice of pharmaceutical products; and, the second level of the hierarchy represents the factors, namely, quality of products, variety of products, availability of products, delivery deadline, flexibility in quantity, competitive price. The elements in the AHP hierarchy for the present study and the pair-wise comparison scale are displayed in Figure 1 and Table 1, as shown below:

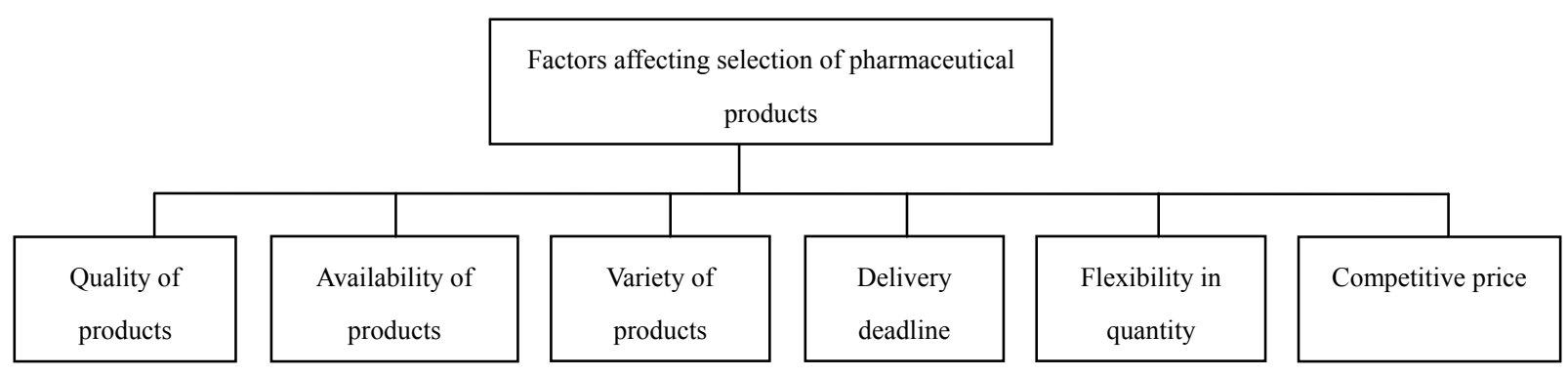

Figure 1. AHP hierarchy process

Table 1. Pair-wise comparison scale for AHP preferences

\begin{tabular}{ll}
\hline Numerical rating & Verbal Judgments of Preferences \\
\hline 9 & Extremely preferred \\
7 & Very strongly preferred \\
5 & Strongly preferred \\
3 & Moderately preferred \\
1 & Equally preferred \\
$2,4,6,8$ & Ratings in between \\
\hline
\end{tabular}

\subsection{Data Collection and Data Analysis}

In this study, the AHP questionnaire is prepared with the six factors affecting the customer requirements in selecting pharmaceutical products. This questionnaire is delivered to a group of executives, working in the production and marking department, who have in-depth knowledge and experiences regarding retailer preferences in choosing products. The respondents fill out the questionnaire using the pair-wise comparison scale as mentioned above. In filling it out, it is necessary to have the responses in only one side of the diagonal, since the values on the other side are the inverse of the former. Table 2 presents the response to the questionnaire filled out by the group of executives.

Table 2. Pair-wise comparison matrix of the selected criteria

\begin{tabular}{|c|c|c|c|c|c|c|c|c|c|c|}
\hline & $\begin{array}{l}\text { Quality } \\
\text { products }\end{array}$ & of & $\begin{array}{l}\text { Availability } \\
\text { products }\end{array}$ & of & $\begin{array}{l}\text { Variety } \\
\text { products }\end{array}$ & of & $\begin{array}{l}\text { Delivery } \\
\text { deadline }\end{array}$ & $\begin{array}{l}\text { Flexibility } \\
\text { quantity }\end{array}$ & in & Competitive price \\
\hline $\begin{array}{l}\text { Quality of } \\
\text { products }\end{array}$ & 1 & & 5 & & 3 & & 4 & 7 & & 3 \\
\hline $\begin{array}{l}\text { Availability of } \\
\text { products }\end{array}$ & & & 1 & & $1 / 2$ & & 3 & 2 & & 2 \\
\hline $\begin{array}{l}\text { Variety of } \\
\text { products }\end{array}$ & & & & & 1 & & 6 & 3 & & 3 \\
\hline Delivery deadline & & & & & & & 1 & $1 / 4$ & & $1 / 3$ \\
\hline $\begin{array}{l}\text { Flexibility in } \\
\text { quantity }\end{array}$ & & & & & & & & 1 & & $1 / 3$ \\
\hline Competitive price & & & & & & & & & & 1 \\
\hline
\end{tabular}


Data analysis for AHP is carried out by Expert Choice software version 11.0. It is to be noted that the inconsistency that might arise out of the subjective preferences in dealing with customer choices should not be more than 0.10 .

\section{Study Findings and Discussions}

This section presents the findings and their discussions of AHP techniques. By using pair-wise comparison procedure in AHP, the questionnaires as shown in Table 2 are completed. The weights or the rankings of the six factors are then generated by Expert Choice software. The research reveals that quality of products should be given maximum attention. This factor secured $44 \%$ importance among the six criteria we have chosen. The reason for choosing this factor by the retail pharmacy is customer satisfaction; besides, it also affects corporate performance since customers will buy a product from companies they will be satisfied with, i.e. such products that will meet their expectations (Suchánek \& J. Králová, 2015). According to Jahanshahi et al (2011), there are high positive correlation between the constructs of customer service and product quality with customer satisfaction and loyalty. For this, the retailers' ultimate aim is to have access to suppliers (drug manufacturing company) that ensure certain quality standards.

From the findings, it is found that, the factor 'variety of products' holds the second position with a $20 \%$ importance. Variety of products/brand offers often serves as a quality cue and thus influences which brand consumers choose (Berger, Draganska, \& Simonson, 2007). Rigoglioso (2006) opined that offering a greater array of product options increases the likelihood customers will find what they need and buy. This is also echoed by Trindade (2010) in a study that in the retail sector, in particular, the variety of products in a store is one of the most important factors that consumers consider when deciding where to shop.

The criterion 'availability of product' ranks third with $13 \%$ significance. In this day and age of consumerism, the pharmaceutical industry has become more competitive. People prefer to buy drugs and medicine from a friendly neighborhood pharmacy where they don't have to stand and wait in long queues. For this reason, the system needs to be strengthened by making essential medicines available for patients (Prinja, Bahuguna, Tripathy, \& Kumar, 2015). Now-a-days, the performance of a pharmacy is evaluated by the patients, primarily on the basis of availability of adequate amounts, appropriate dosage forms and needed quality medicines and also the presence of appropriate staff members. Therefore, drugstores should be familiar with generic medicine, branded medicine and even traditional medicine and be able to recommend the right one to their customers.

The fourth important factor is 'flexibility in quantity', getting $10 \%$ importance. In pharmaceutical sector, as the competitive landscape has shifted from traditional skills on research and development and on sales and marketing into flexible, cost-efficient, and functional system, it is necessary to consider operational capabilities. Pharmaceutical companies are required to manage product demand volatility by implementing pack-to-order strategies where drugs are packed to order in late stages of manufacturing on the basis of local demand (Ehrhardt, Hutchens, \& Higgins, 2012). This system would facilitate thedrug store to improve their quality of storage and inventory management systems.

The role of competitive price comes next with $9 \%$ importance. For the successful functioning of drug store, it is important to provide easy access to affordable and effective medicine to the individual and community people. Simultaneously, as because medicines and pharmaceutical products generally affect the lives and health of people, to avoid the risk of buying fake medicines, many consumers are more than willing to pay a higher price as long as the quality of the products they buy is assured. Kim (2015) in a study opined that manufacturers should recognize that even though customers are willing to pay more for higher quality products, and for variety, they are also sensitive about the price.

Though 'delivery deadline' scores the lowest, acquiring only 5\% significance among the six factors in our study, this factor should not be compromised because one of the major challenges faced by a pharmaceutical company is to maintain the optimum delivery schedules and meet the set deadlines. In addition, care should be taken about the location of warehouse and distribution at various overseas and domestic locations. In the pharmaceutical supply chain, the retail pharmacies play a critical role and drug manufacturers increasingly rely on this channel to market and sell their product to a varied customer base.It is thus an obligation on the part of a drug manufacturing company to ensure the delivery of right drug, at the right time and place, in the right condition to its retail pharmacies.

As shown in Figure 3, the highest priority is attributed to the quality of products $(0.435)$, followed by variety of products $(0.201)$, availability of products $(0.128)$, flexibility in quantity $(0.101)$, competitive price $(0.086)$ and 
delivery deadline (0.049). As revealed by the synthesis output, the value of the overall inconsistency is 0.09 , which is lower than the threshold value of less than 0.10 , thus lending credence to the reliability of the result.

Synthesis with respect to:

Goal: Critical Factors Affecting Choice of Pharmaceutical Products

Overall Inconsistency $=.09$

$\begin{array}{ll}\text { Flexibility in Quantity } & .101 \\ \text { Availability of Product } & .128 \\ \text { Variety of Product } & .201 \\ \text { Deliverv Deadline } & .049 \\ \text { Competitive Price } & .086 \\ \text { Quality of Product } & .435\end{array}$

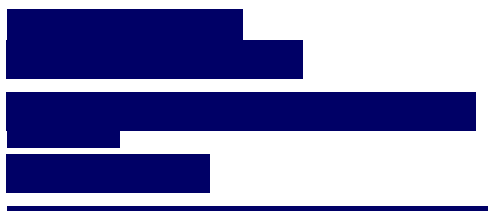

Figure 3. Ranking of the factors affecting customer choice as generated by expert choice

\section{Conclusions and Suggestions for Future Research}

Customer satisfaction holds paramount importance in the competitive business world. For this, it is necessary for companies to be innovative in product design, manufacturing, and marketing that reflect customer requirements and satisfy them as well. In this regard, the present study is conducted to prioritize the factors affecting the choice of retail pharmacies in Bangladesh while purchasing the drugs from various pharmaceutical companies. Six factors are identified and then analyzed byanalytic hierarchy process (AHP), a widely used framework in decision making process that quantifies the qualitative factors through a standard scale. For this, Expert Choice software version 11.0 is employed. The results indicate that quality of product criterion is ranked first with an overall priority score of $44 \%$; this is followed by variety of product with around $20 \%$, availability of product, flexibility in quantity, and competitive price are ranked third, fourth, and fifth with about $13 \%, 10 \%$, and $9 \%$ respectively. Delivery deadline turns out to be of least importance having a weight of $5 \%$ only.

Though the study covers many aspects affectingthe retailers' decision making in selecting the pharmaceutical products, it has some limitations as well that can be addresses in future research works. These are stated below:

- The current study identified six factors having a good impact on decision making. However, these factors can also thoroughly be investigated. In this context, factor analysis might be conducted to find out the constituent items representing each of these six factors. Besides, other factors, such as brand loyalty, trust, physician's choice, etc. can be taken into consideration in future study.

- One of the main operations of AHP is hierarchy construction. However, no sub-criteria or the alternatives are considered in this study. In order to get a greater insight, this issue can be taken into account in any future research.

- $\quad$ The present study might be extended by considering the integration of QFD (Quality Function Deployment) with AHP, whereby various technical aspects can be identified to satisfy the customer requirements.

- Purchasing activity of pharmaceutical drugs runs along the physician-pharmacist-patient continuum, where physicians are at the core of the system. The current study, however, has taken retail pharmacy only as the customer base. In this regard,physicians' preferences might be considered in any future work.

\section{References}

Ahmed, G. T. (2015, March 08). Pharma exports in fast lane. Retrieved from http://www.thedailystar.net/pharma-exports-in-fast-lane-39917

Bangladesh Bureau of Statistics.(2013). Statistical Year Book, Bangladesh. Retrieved from http://www.bbs.gov.bd/

Bangladesh's Corporate World. (2013). Growth of Pharmaceutical sector of Bangladesh. Retrieved from http://bangladesh-corporate-world.blogspot.com/2013/11/growth-of-pharmaceutical-sector-of.html

Berger, J., Draganska, M., \& Simonson, I. (2007).The Influence of Product Variety on Brand Perception and Choice.Marketing Science, 26(4), 460-472.

Castelló, A. M. (2003). Demand for Pharmaceutical Drugs: A Choice Modelling Experiment. Barcelona Dep. 
d'Economia i Empresa, UPF 704.

David Asamoah, E. A. (2012). International Journal of Business and Management, 7(10).http://dx.doi.org/10.5539/ijbm.v7n10p49

Directorate General of Drug Administration. (2013). Retrieved March 13, 2016, from http://www.dgda.gov.bd/index.php/faq

Ehrhardt, M., Hutchens, R., \& Higgins, S. (2012). Five steps towards a Revitalized Pharmaceutical Supply Chain. Booz and Company (66).https://www.strategy-business.com/article/00094?gko=982c0

Enyinda, E. A. (2010). A Model for Quantifying Strategic Supplier Selection: Evidence from a Generic Pharmaceutical Firm Supply Chain. International Journal of Business, Marketing and Decision Sciences, 3(2).https://pdfs.semanticscholar.org/9fc9/2b58a4cdb93f19a69c488c45dca286ba5bcb.pdf

Gennaro, A. (1990). Remington's Pharmaceutical Sciences (18thed.). PA, Easton: Mack Publishing Company.http://www.worldcat.org/title/remingtons-pharmaceutical-sciences/oclc/24381485

Ghatari, A. R., Mehralian, G., Zarenezhad, F., \&Rasekh, H. R. (2013).Developing a Model for Agile Supply: an Empirical Study from Iranian Pharmaceutical Supply Chain.Iranian Journal of Pharmaceutical Research, 12(supplement), 193-205. https://www.ncbi.nlm.nih.gov/pmc/articles/PMC3813359/

Haque, M., Anam, S., \& Ahmed, S. (2014). A Conceptual Framework of Supplier Selection and Order Allocation: An Integrated Methodology of AHP and LP Modeling. A Conceptual Framework of Supplier Selection and Order Allocation: An Integrated Methodology of AH. Journal of Global Business Issues, 8(2).https://www.highbeam.com/doc/1P3-3587934021.html

IDLC Investment Limited. (2013). Pharmaceutical Industry of Bangladesh.Retrieved from http://www.idlc.com/sector_coverage/1403168758Research\%20Report\%20on\%20Pharmaceutical\%20Sect or\%20of\%20Bangladesh\%20-\%20Update\%20-\%202013.pdf

Jaberidoost et al. (2015).Pharmaceutical Supply Chain risk assessment in Iran using Analytical Hierarchy Process (AHP) and Simple Additive Weighting (SAW) Methods.Journal of Pharmaceutical Policy and Practice, 8(9).https://www.ncbi.nlm.nih.gov/pmc/articles/PMC4354976/

Jahanshahi, A. A., Gashti, M. A., Mirdamadi, S. A., Nawaser, K., \&Khaksar, S. M. (2011). Study the Effects of Customer Service and Product Quality on Customer Satisfaction and Loyalty. International Journal of Humanities and Social Science, 1 . http://www.ijhssnet.com/journals/Vol__1_No._7_[Special_Issue_June_2011]/33.pdf

Kamath, J., Kamath, K. K., Azharuddin, M., Subramanyam, E. V., \&Shabharaya, A. R. (2012). American Journal of Pharmatech Research, 2(4), 281-287.http://www.ajptr.com/archive/volume-2/august-2012-issue-4/article-292.html

Kim, Y. A. (2015). The Impact on Customers' Perception of Product Variety.Retrieved March 15, 2016, from http://gsis.korea.ac.kr/wp-content/uploads/2015/04/9-1-3-Kim.pdf

Matthews, M. (2001). Who's Afraid of Pharmaceutical Advertising? A Response to a changing Health Care System. Policy Report \#155, Institute for Policy Innovation. http://www.ipi.org/docLib/PR155-PharmAdvertising-FINAL..pdf-OpenElement.pdf

Miller, R., \& Goodman, C. (2016). Performance of retail pharmacies in low- and middle-income Asian settings: A systematic review. Journal of Health Policy and System Research.https://doi.org/10.1093/heapol/czw007

Prinja, S., Bahuguna, P., Tripathy, J. P., \& Kumar, R. (2015).Availability of Medicines in Public Sector Health Facilities of Two North Indian States.BMC Pharmacology and Toxicology.https://doi.org/10.1186/s40360-015-0043-8

Rigoglioso, M. (2006).When Customers Equate Choice with Quality.Retrieved March 15, 2016, from https://www.gsb.stanford.edu/insights/when-customers-equate-choice-quality

Saaty, T. L. (2000). Fundamentals of Decision Making and Priority Theory with the Analytic Hierarchy Process.RWS

Publications.https://books.google.com.bd/books/about/Fundamentals_of_Decision_Making_and_Prio.html? id $=$ wct10TlbbIUC\&redir_esc $=$ y

Strong, S. J. (2014). Rethinking Strategy in Pharmacy and Drugstore Retailing. Retrieved from http://www.babson.edu/executive-education/thought-leadership/retailing/Pages/rethinking-strategy.aspx 
Subramaniam, R. (2012, August). A Review of Applications of Analytic Hierarchy Process in Operations.International Journal of Production Economics, 138(2).http://www.academia.edu/6485034/A_review_of_applications_of_Analytic_Hierarchy_Process_in_ operations_management

Suchánek, P. R., \&Králová, J. M. (2015).Customer Satisfaction, Product Quality and Performance of Companies.Review of Economic Perspectives-NARODOHOSPODARSKY, 14(4), 329-344. https://doi.org/10.1515/revecp-2015-0003

Tas, A. (2012, April 11). A Fuzz AHP Approach for Selecting a Global Supplier in Pharmaceutical Industry.African Journal of Business 5073-5084.http://www.academicjournals.org/article/article1380707073_Tas.pdf] [https://doi.org/10.5897/AJBM11.2939

Triantaphyllou, E., \& Mann, S. H. (1995).Using the Analytical Hierarchy Process for Decision Making Engineering Applications: Some Challenges.International Journal of Industrial Engineering: Applications and Practice, 2(1), 35-44. http://bit.csc.lsu.edu/trianta/Journal_PAPERS1/AHPapls1.pdf

Trindade, A. (2010). Price and Variety in Supermarkets: Can Store Competition Hurt Consumers? Retrieved from http://www.eco.uc3m.es/temp/Trindade.pdf

Vidal, L. A., Shahin, E. M., Berhoune, M., \&Bonan, B. (2010).Applying AHP to select drugs to be produced by anticipation in a chemotherapy compounding unit.Expert Systems with Applications, (37), 1528-1534. https://doi.org/10.1016/j.eswa.2009.06.067

Yadav. (2015). Supplier Selection by AHP in KMC Pharmaceutical: Use of GMIBM Method for Inconsistency Adjustment. Journal of Management Research, 7(5).https://doi.org/10.5296/jmr.v7i5.8044

Zhang, Y., \& Soumerai, S. B. (2007). Do newer Prescription Drugs Pay for Themselves? A Re-assessment of the Evidence. Health Affairs, 26(1), 880-886.https://doi.org/10.1377/hlthaff.26.3.880

\section{Copyrights}

Copyright for this article is retained by the author(s), with first publication rights granted to the journal.

This is an open-access article distributed under the terms and conditions of the Creative Commons Attribution license (http://creativecommons.org/licenses/by/4.0/). 